\title{
New Pulmonary Therapies Directed at Targets Other than CFTR
}

\author{
Scott H. Donaldson ${ }^{1}$ and Luis Galietta ${ }^{2}$ \\ ${ }^{1}$ Cystic Fibrosis Research and Treatment Center, University of North Carolina at Chapel Hill, Chapel Hill, \\ North Carolina 27599 \\ ${ }^{2}$ Lab. di Genetica Molecolare, Instituto Giannina Gaslini, 16148 Genova, Italy \\ Correspondence: scott_donaldson@med.unc.edu
}

Our current understanding of the pathogenesis of cystic fibrosis (CF) lung disease stresses the importance of the physical and chemical properties of the airway surface liquid (ASL). In particular, the loss of cystic fibrosis transmembrane conductance regulator (CFTR) chloride channel function in CF reduces the volume and fluidity of the ASL, thus impairing mucociliary clearance and innate antimicrobial mechanisms. Besides direct approaches to restoring mutant CFTR function, alternative therapeutic strategies may also be considered to correct the basic defect of impaired salt and water transport. Such alternative strategies are focused on the restoration of mucociliary transport by (1) reducing sodium and fluid absorption by inhibiting the $\mathrm{ENaC}$ channel; (2) activating alternative chloride channels; and (3) increasing airway surface hydration with osmotic agents. Therapeutic approaches directed at targets other than CFTR are attractive because they are potentially useful to all patients irrespective of their genotype. Clinical trials are underway to test the efficacy of these approaches.

$T_{\text {the }}$ he study of the normal physiologic processes that contribute to innate lung defenses has allowed the identification of important defects involved in the pathogenesis of cystic fibrosis (CF) lung disease. There is substantial evidence that mucociliary clearance is perhaps the most important initial line of lung defense and that defective mucociliary clearance is responsible for the development and progression of the chronic lung disease that typifies CF. It is important, therefore, to review the elements that compose the mucus-clearance apparatus.

In the last 30 years, a series of studies revealed the importance of the airway-lining fluid for defense against microbial pathogens. This airway-surface liquid layer (ASL) is composed of two layers: a periciliary layer (PCL), containing water, low-molecular-weight ions, and a complex collection of secreted and cell-surfacetethered proteins; and an overlying mucus layer, primarily composed of secreted mucins. Acting in concert with secreted antimicrobial substances (e.g., lysozyme, lactoferrin, and defensins), the mucus layer efficiently traps and clears inhaled pathogens and particulates. The PCL, in turn, provides a lubricant layer, in which cilia can beat freely to propel the mucus layer toward the mouth. Proper regulation of ASL volume,

Editors: John R. Riordan, Richard C. Boucher, and Paul M. Quinton

Additional Perspectives on Cystic Fibrosis available at www.perspectivesinmedicine.org

Copyright (C) 2013 Cold Spring Harbor Laboratory Press; all rights reserved; doi: 10.1101/cshperspect.a009787

Cite this article as Cold Spring Harb Perspect Med 2013;3:a009787 
therefore, facilitates cilia motion and ensures adequate hydration of its component layers. Both attributes are critical to the maintenance of mucus clearance.

Although fluid may be donated to the ASL compartment via the distal lung compartment and submucosal glands, the superficial epithelia play a key role in regulating ASL volume through its capacity to initiate both liquid absorption and secretion. The absorption of ASL is accomplished via active sodium transport, with the apical epithelial sodium channel $(\mathrm{ENaC})$ mediating the rate-limiting step in this process. Liquid secretion across the superficial epithelium is conducted through cystic fibrosis transmembrane conductance regulator (CFTR) and calcium-activated chloride channels (CaCC). CFTR appears to play a central role in this process: it is the primary pathway for chloride secretion under basal conditions, and it also regulates the activity of $\mathrm{ENaC}$ via mechanisms that are still being elucidated. By regulating liquid absorption and secretion, CFTR ensures that the PCL remains at least $7 \mu \mathrm{m}$ thick (approximating the height of cilia) and that the mucus layer is adequately hydrated for transport.

The importance of CFTR as a homeostatic regulator of ASL volume is demonstrated by the severe consequences observed in CF patients. CF epithelia hyperabsorb liquid because of dysregulation of $\mathrm{ENaC}$ and the absence of capacity to secrete liquid through CFTR (Stutts et al. 1995). As demonstrated by studies using primary cell cultures, these ion-transport abnormalities result in an abnormally shallow PCL, which in turn causes spontaneous mucus transport to stop (Matsui et al. 1998). Though it is certain that chloride secretion through $\mathrm{CaCC}$ can partially compensate for the loss of CFTR (Tarran et al. 2002), the system is vulnerable to insults (e.g., viral infection) that, over time, result in the accumulation of poorly clearing lung regions and mucus obstruction (Tarran et al. 2005). ASL dehydration and impaired mucus transport are believed to create a favorable environment for the initial acquisition and subsequent proliferation of bacteria in the airways. Developing therapies that correct these ion-transport abnormalities, therefore, may provide the means to prevent or delay the onset and progression of CF lung disease.

\section{TARGETING CFTR}

Over the past decade, many efforts have been aimed at developing strategies to recover mutant CFTR function. In this respect, it must be considered that CF mutations cause loss of CFTR function by different mechanisms, including impaired exit of the protein from the endoplasmic reticulum and/or defective channel gating. Therefore, CFTR-directed therapies must be tailored to specific mutations, or groups of mutations, sharing the same type of functional defect. For example, pharmacological agents called potentiators, able to stimulate CFTR channel opening, have been developed to treat patients carrying mutations that impair CFTR gating, such as G551D. The potentiator VX-770 (Vertex Pharmaceuticals) has been tested in phase II and III clinical trials with positive results (Accurso et al. 2010). Pharmacological correctors, aimed at the rescue of mutant CFTR (e.g., $\Delta$ F508CFTR) from the endoplasmic reticulum and encouraging ribosomal read-through of abnormal stop mutations, are also undergoing clinical trials, as are combinations of correctors and potentiators. The approaches used to target CFTR directly are covered much more extensively elsewhere.

Whereas targeting CFTR might be the most rational and effective approach to fully restoring ion transport in CF, therapeutics aimed at different targets are also under active investigation. Although indirect, this approach has potential advantages when compared to CFTR-directed therapies. First, this approach utilizes receptors and ion channels that are known to be expressed at appropriate cellular locations and, therefore, do not require us to replace or restore CFTR at the apical membrane. Second, effective restoration of airway surface hydration by targeting proteins other than CFTR is expected to be beneficial for all CF patients, irrespective of their type of mutation. Fortunately, a number of potential therapeutic targets are available, which provide significant hope for developing novel, effective treatments for CF lung disease (Fig. 1). 
New Pulmonary Therapies

ENaC inhibition
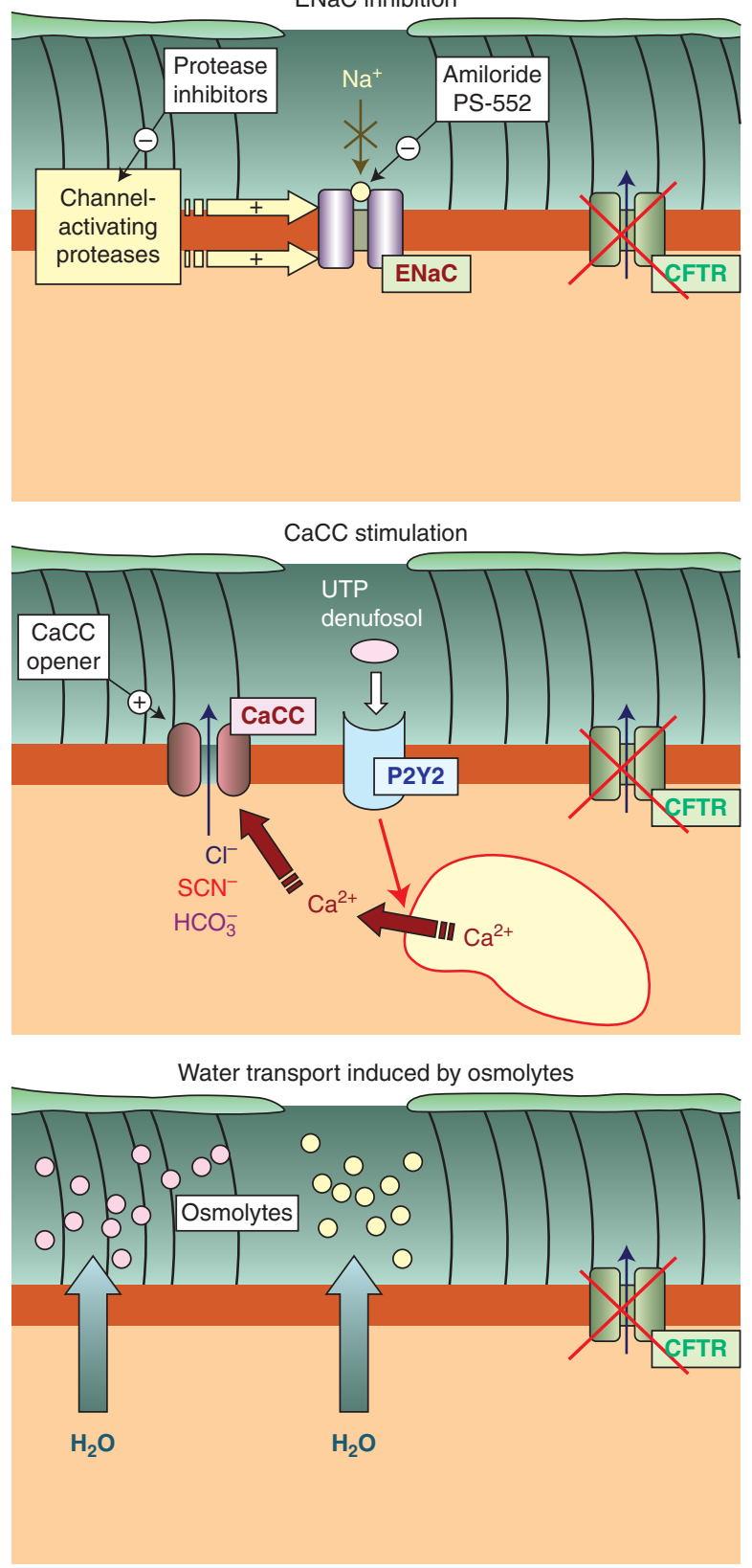

Figure 1. Three alternative strategies to correct the intrinsic airway surface liquid defect (ASL) in cystic fibrosis. (Top) Inhibition of sodium absorption through ENaC may be obtained by direct inhibition of the channel (e.g., with amiloride or analogs) or by preventing its activation mediated by proteases. (Middle) Stimulation of calcium-activated chloride channels (CaCCs) by direct activators (openers) or by inducing intracellular calcium elevation through a surface receptor (e.g., the purinergic P2Y2 receptor) is another potential way to promote ASL normalization in CF. (Bottom) Improved hydration of airway surfaces can be obtained by aerosolized osmolytes (e.g., hypertonic saline or mannitol). 
S.H. Donaldson and L. Galietta

\section{TARGETING ENaC}

One of the possible therapeutic targets outside of CFTR is ENaC. Sodium hyperabsorption through $\mathrm{ENaC}$ has been described as a primary pathophysiologic feature of CF epithelia. The data supporting this conclusion come from a variety of in vitro and in vivo systems, including nasal and lower-airway potential-difference measurements (Knowles et al. 1981) and shortcircuit current measurements in excised and cultured tissues (Willumsen and Boucher 1991). Following these observations, a mouse model was created that, with overexpressed $\beta$-subunit of $\mathrm{ENaC}$ in its airways, was used to test the hypothesis that sodium hyperabsorption was sufficient to cause a CF-like lung disease (Mall et al. 2004). Indeed, these mice developed PCL depletion and mucus obstruction. Similarly, deletion of Nedd4 L, a ubiquitin ligase involved in down-regulation of $\mathrm{ENaC}$, also led to the development of $\mathrm{Na}^{+}$hyperabsorption and a CF-like lung phenotype (Kimura et al. 2011). Identification of the mechanism(s) underlying sodium hyperabsorption in CF, however, has been a difficult and sometimes contentious problem. Recently, it appears that CFTR expression (wild type, but not $\Delta$ F508) prevents proteolytic activation of the $\alpha$ - and $\gamma$-ENaC subunits by endogenous proteases involved in the normal regulation of this channel (Gentzsch et al. 2010). Because ENaC and CFTR coimmunoprecipitate, this relationship could result from a direct physical association or from the formation of a regulatory complex. Additional disruption of $\mathrm{ENaC}$ regulation by endogenous proteases may come from changes in the ASL environment itself in CF (Myerburg et al. 2006; Tarran et al. 2006). It has been shown that $\mathrm{ENaC}$ activity responds to changes in the volume and/or composition of the overlying ASL (Myerburg et al. 2010). Dilution of the thin lining fluid on airways leads to a rapid upregulation of $\mathrm{ENaC}$ activity, whereas progressive ASL absorption is normally associated with reduced $\mathrm{ENaC}$ activity. It has become increasingly clear that, in $\mathrm{CF}$, the balance between serine protease and antiprotease activity is disrupted, causing full proteolytic activation of $\mathrm{ENaC}$, even under low ASL volume conditions where down-regulation of $\mathrm{ENaC}$ activity would be expected and desirable.

Although altered levels of protease and antiprotease activities could account for these findings, other factors may also be involved. For example, SPLUNC1 - a highly expressed, secreted protein-was found to bind to $\mathrm{ENaC}$ and protect it from proteolytic cleavage/activation (Garcia-Caballero et al. 2009; Rollins et al. 2010). While not possessing intrinsic antiprotease activity itself, alterations in the expression or binding of SPLUNC to ENaC could also result in constitutive activation of $\mathrm{ENaC}$ by endogenous proteases.

The evidence that sodium hyperabsorption contributes to ASL volume depletion in CF makes $\mathrm{ENaC}$ activity an attractive therapeutic target. Most simply, this could be accomplished through the use of inhaled $\mathrm{ENaC}$ blockers, such as amiloride (Knowles et al. 1990). The major challenge facing this approach is achieving the desired drug effectiveness and durability in the lung while avoiding systemic exposure that could lead to unwanted renal effects (i.e., hyperkalemia) (Knowles et al. 1992). One potential criticism of this therapeutic approach is that while slowing sodium/volume absorption might be desirable in CF, if adequate chloride/ volume secretion does not accompany it, the desired improvements in ASL hydration and mucociliary clearance (MCC) might not be achieved. The combination of an $\mathrm{ENaC}$ inhibitor with a secretagogue (e.g., a hyperosmotic agent or $\mathrm{CaCC}$ stimulator), therefore, might be more beneficial.

A second approach to preventing sodium hyperabsorption is to block proteolytic activation of $\mathrm{ENaC}$, which appears to be dysregulated in CF airways (Tarran et al. 2006; Myerburg et al. 2008). Peptide and small molecule inhibitors of relevant proteases have been proposed for this purpose, with supportive data from in vitro and animal studies (Bridges et al. 2001; Coote et al. 2009). However, testing the safety and efficacy of this approach in humans has yet to be accomplished. This approach is complicated by the fact that multiple endogenous proteases appear to be able to activate $\mathrm{ENaC}$ (e.g., prostasin, TMPRSS4, matriptase) under normal condi- 
tions (Donaldson et al. 2002; Vuagniaux et al. 2002; Garcia-Caballero et al. 2008), and activation by neutrophil elastase in the highly inflamed CF airway is also possible (Caldwell et al. 2005). It is likely that a broad-spectrum antiprotease, or knowledge that selective inactivation of a key protease in a signaling cascade would be effective, will be needed. Alternatively, given the recent data that CFTR and/or SPLUNC shield ENaC from proteolysis by several proteases expressed in cell culture systems, a therapeutic approach that leverages this knowledge could be conceived of as well.

\section{CLINICAL STUDIES OF ENaC INHIBITORS}

Clinical studies of inhaled amiloride, the prototype channel blocker, showed acute improvements in mucociliary clearance (Kohler et al. 1986) but little to no improvement in lung function or other clinically meaningful parameters (Knowles et al. 1990; Graham et al. 1993). Because amiloride has a short half-life in airways, likely limiting its efficacy, efforts have been made to develop more potent and longer-acting analogs. One blocker, PS552-02 (Parion Sciences), has entered phase II trials in CF (Hirsh et al. 2008). This compound is roughly 60 -fold more potent than amiloride at blocking $\mathrm{ENaC}$ currents in cultured human airway cells, and it has also demonstrated a significantly increased ability to stimulate MCC in a sheep model. Importantly, whereas the effect of amiloride had waned by $4 \mathrm{~h}$ postdose in this model, PS55202 continued to demonstrate an effect on clearance. Similar effects on MCC were demonstrated in healthy human volunteers (Donaldson et al. 2005), and preliminary reports of a multidose study in CF subjects did not reveal major safety concerns. Whether the regular use of this or other $\mathrm{ENaC}$ inhibitors currently being developed results in clinically important outcomes has not yet been demonstrated.

The concept that agents from different drug classes (e.g., osmotic agent or $\mathrm{P}_{2} \mathrm{Y}_{2}$ agonist with an $\mathrm{ENaC}$ blocker) might yield additive or synergistic results is quite appealing. Although attractive, these approaches will require careful clinical testing. Interestingly, the combination of amiloride and hypertonic saline (HS) did not yield any additional improvements over HS alone, and in fact appeared to inhibit the beneficial effects of HS on MCC and lung function (Donaldson et al. 2006). Subsequent in vitro experiments suggested that off-target effects of amiloride in CF epithelia (i.e., reductions in osmotically driven water transport) may have prevented the expected ASL volume responses to HS that would lead to augmented MCC improvements. Similar in vitro studies with PS55202 have not shown evidence of comparable offtarget activities, and indeed pretreatment before HS administration increases the peak ASL volume response and extends the duration of ASL volume expansion (Hirsh et al. 2008). We await clinical trials to further test the concept that combination therapy may be useful in CF.

\section{TARGETING ALTERNATIVE CHLORIDE CHANNELS}

The molecular identity of $\mathrm{CaCC}$ has remained elusive for many years (Galietta 2009). However, three independent studies in 2008 identified TMEM16A, also known as anoctamin-1, as a membrane protein responsible for $\mathrm{CaCC}$ activity (Caputo et al. 2008; Schroeder et al. 2008; Yang et al. 2008). Expression of TMEM16A by transfection in null cells (i.e., devoid of endogenous activity of CaCCs) causes the appearance of CaCC-like membrane currents. Conversely, silencing TMEM16A expression in airway epithelial cells via RNA interference causes significant inhibition of calcium-dependent chloride secretion. These observations indicate that TMEM16A is an important component of $\mathrm{CaCCs}$.

However, there are still several unanswered questions. First, it is not clear whether TMEM16A is directly activated by calcium or if another protein, such as calmodulin, represents the "calcium sensor" (Tian et al. 2011). It is also possible that activation by calcium involves a phosphorylation event, as indicated by some studies (Wagner et al. 1991; Xie et al. 1996). In other cases, phosphorylation seems to have an inhibitory role, leaving this issue unresolved (Wang and Kotlikoff 1997; Greenwood 
et al. 2001). Obviously, elucidation of CaCC regulation mechanisms is important if we are to devise pharmacological strategies that lead to stimulation of alternative chloride transport in CF cells. The recent identification of TMEM16A may help our understanding of the molecular mechanisms affecting CaCC function.

The TMEM16A discovery also opens the possibility of finding pharmacological activators that can directly open $\mathrm{CaCC}$ channels without altering cytosolic calcium. For this purpose, TMEM16A-expressing cells could be utilized in high-throughput screenings of large chemical libraries, as has been done to identify activators and inhibitors of the CFTR channel (Verkman and Galietta 2009). However, it is important to note that a recent study has questioned the role of TMEM16A as a CaCC protein in airway epithelia. According to this study, a selective TMEM16A inhibitor was able to strongly block calcium-dependent chloride secretion in salivary glands but had minor effects on bronchial epithelial cells (Namkung et al. 2011). This finding would suggest that another protein, not TMEM16A, is responsible for CaCC activity in airway epithelial cells. But this conclusion contrasts with the findings of other studies. For example, silencing TMEM16A in human bronchial epithelial cells caused a significant decrease in calcium-dependent chloride secretion (Caputo et al. 2008). Furthermore, chloride secretion and MCC were also significantly decreased in TMEM16A knockout mice (Ousingsawat et al. 2009; Rock et al. 2009). Additional studies are required to resolve these controversial findings.

Despite lacking knowledge of the molecular identify of CaCC, early studies indicated that airway epithelia possessed a chloride secretory pathway other than CFTR (Anderson and Welsh 1991; Mason et al. 1991). In these studies, increases in cytosolic calcium by different agonists caused the activation of chloride channels with biophysical and pharmacological properties distinct from those of CFTR. Experiments in CF epithelia provided the most conclusive demonstration that CaCCs and CFTR represent separate entities (Anderson and Welsh 1991; Knowles et al. 1991; Mason et al. 1991). Such cells had CaCC-dependent membrane currents but no cAMP-activated chloride transport. In vitro measurements of the PCL height with a confocal microscope also demonstrated that CaCCs have the ability to influence airway surface hydration (Tarran et al. 2005). Stimulation of these channels by calcium agonists evokes a transient increase in PCL thickness and improvement in mucociliary transport in both normal and CF epithelia. This is a clear indication that stimulation of alternative chloride channels may, at least in part, compensate the CFTR defect.

How CaCC compensates for the lack of functional CFTR in CF is not completely established. In fact, it is not clear whether these two channels have fully overlapping physiological functions. In this respect, it has been shown that CFTR transports anions other than chloride that may have crucial physiological functions. For example, secretion of bicarbonate through CFTR (Smith and Welsh 1992; Illek et al. 1997) could be important in the expansion of mucins following exocytosis (Garcia et al. 2009) and in the regulation of PCL pH (Coakley et al. 2003). CFTR activity has also been directly linked to an antimicrobial function. Indeed, CFTR is permeable to thiocyanate, a physiological anion that is actively transported through the basolateral membrane by a sodium-coupled mechanism (Fragoso et al. 2004). When secreted onto the apical surface of the epithelium, thiocyanate is converted to hypothiocyanite by lactoperoxidase, an enzyme that also consumes hydrogen peroxide as the second substrate (Gerson et al. 2000). Hypothiocyanite has been reported to be an effective bactericidal molecule. Therefore, impaired thiocyanate transport through CFTR could generate a deficit in an important innate defense mechanism (Conner et al. 2007; Moskwa et al. 2007). Reassuringly, activation of CaCCs could provide a route not only for chloride secretion, but also for $\mathrm{HCO}_{3}{ }^{-}$ and $\mathrm{SCN}^{-}$transport. However, consideration of $\mathrm{CaCC}$ as a suitable drug target to circumvent the CFTR defect requires a better understanding of $\mathrm{CaCC}$ structure, regulation, and function.

In the absence of direct $\mathrm{CaCC}$ activators, strategies aiming at the stimulation of alternative 
chloride transport in the airway epithelium have been based on the mobilization of cytosolic calcium. One of the most effective ways to promote intracellular calcium increase in airway epithelial cells is by stimulation of purinergic receptors (Mason et al. 1991). Administration of ATP or UTP to the apical surface of the epithelium binds to the $\mathrm{P} 2 \mathrm{Y}_{2}$ nucleotide receptor and causes a rapid increase in cytosolic free calcium concentration and activation of CaCCs. The resulting increase in chloride secretion reaches a peak within a few seconds, though the largest part of this lasts for only 5-15 min (Mason et al. 1991; Galietta et al. 2002). The transient nature of this effect is likely multifactorial. First, ATP and UTP are rapidly hydrolyzed by ectoenzymes (Picher et al. 2004). Second, calcium mobilization is intrinsically transient because it is largely dependent on release from intracellular calcium stores (Mason et al. 1991). Third, desensitization mechanisms may affect purinergic receptors (Clarke et al. 1999) as well CaCCs themselves. Whether these factors impact the suitability of the purinergic receptor as a therapeutic target is unknown.

\section{CLINICAL STUDIES UTILIZING CaCC PATHWAYS}

To attempt to take advantage of the CaCC pathway in $\mathrm{CF}$, inhaled $\mathrm{P} 2 \mathrm{Y}_{2}$ receptor agonists were developed, thus providing an opportunity to circumvent the CFTR-mediated chloride secretory defect. This approach has the additional potential benefits of increasing cilia beat frequency and mucus secretion. While exogenous UTP, a natural ligand for this receptor, was able to potently stimulate mucociliary clearance in vivo in non-CF subjects (Olivier et al. 1996; Noone et al. 1999), it was less efficacious as a monotherapy (i.e., without amiloride) in CF (Bennett et al. 1996). One logical explanation for this discrepancy was that UTP is rapidly degraded by the abundant extracellular nucleotidases found in CF secretions.

A longer acting agonist, denufosol, was subsequently synthesized to resist metabolism in the $\mathrm{CF}$ airway. Following the completion of a series of promising phase II studies (Deterding et al.
2005, 2007), two phase III studies were performed. In the first (TIGER-1), 352 patients were randomized to denufosol or placebo. As a function of the study design, these patients were relatively young (mean age $14.2 \mathrm{yr}$ ) and had mild lung disease (baseline $\mathrm{FEV}_{1} 92 \%$ of predicted). After 24 wk of therapy, a small but statistically significant improvement in $\mathrm{FEV}_{1}(0.045 \mathrm{~L}$; $p=0.047)$ was observed, without significant effects on other lung function parameters (FVC, $\mathrm{FEF}_{25-75}$ ) or on the already low exacerbation frequency. Continued improvement in the raw $\mathrm{FEV}_{1}$ values occurred during the subsequent 24-wk open label extension period (Accurso et al. 2011).

Following these results, a second phase III study (TIGER-2) that included a 48-wk placebo-controlled treatment period and 466 patients was conducted. These patients were similar to those studied in TIGER-1, with respect to their mild severity of lung disease and the intensity of baseline treatment regimen. Unfortunately, preliminary results from this study revealed no difference between denufosol- and placebo-treated subjects in lung function improvement, rate of lung function change over time, or time to first exacerbation frequency.

Why this program failed to achieve drug registration could relate to a number of factors. First, the adequacy of the drug itself (e.g., inadequate potency or durability in the CF lung) or appropriateness of the target (e.g., receptor/ channel already occupied/activated in vivo; receptor target or signaling pathway desensitizes) could be questioned. Second, inadequate delivery to a critical lung compartment (i.e., small airways); or trial design issues (i.e., targeting patients with very mild disease, where $\mathrm{FEV}_{1}$ and exacerbation endpoints may be difficult to impact) could also be problematic. Because these issues will also impact the development of other inhaled agents that target non-CFTR ion channels, they deserve additional scrutiny and study.

Other approaches to the treatment of CF lung disease through modulation of ASL volume via non-CFTR mechanisms continue to be explored. Like denufosol, Moli-1901 (duramycin) is purported to stimulate calcium-activated chloride channels, although the mechanism 
underlying this effect is unclear. Small studies examining nasal potential-difference responses and safety after short-term inhalation use have been conducted and published (Zeitlin et al. 2004; Grasemann et al. 2007). A larger phase IIb dose-ranging study was subsequently initiated in Europe and completed in 2009, but to date no results are available. Clearly, while targeting $\mathrm{CaCC}$ holds promise, clinical benefits have not yet been achieved, and more needs to be learned in order to intelligently design effective therapies.

\section{TARGETING ASL DEHYDRATION VIA OSMOTIC AGENTS}

Perhaps the simplest approach to increasing ASL volume is through the use of osmotically active agents that draw water into the airway lumen across the water permeable airway epithelium (Tarran et al. 2007). HS is one currently available osmotic "hydrator" that has been shown to greatly reduce the frequency of pulmonary exacerbations and to improve lung function (Elkins et al. 2006). The ability of HS to produce these effects in infants and toddlers with CF is currently the subject of a large study spanning North America.

Mannitol, inhaled as a dry powder, is an alternative osmotic. Dry-powder mannitol has been shown to improve mucus rheologic properties of CF sputum (Daviskas et al. 2010) and to stimulate the rate of mucociliary clearance in CF and non-CF bronchiectasis patients (Daviskas et al. 1997, 1999, 2001, 2008; Robinson et al. 1999). As might be predicted, the effect of mannitol on both mucociliary clearance and spirometry outcomes was dose related, with doses $\geq 400 \mathrm{mg}$ being most effective (Daviskas et al. 2008; Teper et al. 2011). A short-term, crossover, phase II study in 39 CF subjects revealed a 7\% improvement from baseline in $\mathrm{FEV}_{1}(121 \mathrm{~mL})$, versus no change during the placebo-treatment period. A rapid fall in lung function back to baseline levels occurred during the 2-wk washout period that followed mannitol treatment (Jaques et al. 2008). Two large, long-term, phase III studies have subsequently been performed in a combined 643 patients from 11 countries. Re- sults from these studies have not yet been published in a peer-reviewed journal, but have been reported at major scientific meetings (Bilton et al. 2009). During 6 mo of double-blinded treatment, mannitol led to an average $7.3 \%$ improvement in $\mathrm{FEV}_{1}$ compared to baseline $(p<$ 0.001 ), and a similar significant improvement when compared to placebo treatment $(p<$ $0.001)$. In contrast to data from a small study by Minasian et al. (2010), patients using rhDNase with mannitol also showed lung function improvement $\left(\mathrm{FEV}_{1} 5.3 \% ; p<0.001\right)$, although this was numerically smaller than the $\mathrm{FEV}_{1}$ change in those not using rhDNase $(9.44 \%$ improvement from baseline). The effect of mannitol on pulmonary exacerbations appears to be smaller than that reported by Elkins et al. (2006) in their study of HS. One possible explanation for this difference could be the more aggressive use of other CF medications (including inhaled antibiotics, rhDNase, and azithromycin) during the mannitol studies, which in turn reduced baseline exacerbation rates and lessened the ability to see an impact on this important clinical outcome measure. Generally speaking, the safety profile of dry-powder mannitol appears to be good, with cough, bronchospasm, oropharyngeal irritation, and hemoptysis being the major reported adverse events. Because mannitol is delivered as a dry powder, the requirement for a nebulizer is obviated, and the treatment time associated with inhaling the required 10 capsules per treatment is $\sim 5 \mathrm{~min}$. On the basis of these findings, dry-powder mannitol (Bronchitol; Pharmaxis) was recently approved for use in Australia.

\section{SUMMARY}

A concerted effort to understand the epithelial ion transport processes that govern ASL formation in normal airways, and the pathophysiologic changes that are responsible for the onset and progression of CF lung disease, has identified several potential therapeutic targets. A multifaceted strategy for finding new CF treatments that leverages this knowledge provides the greatest opportunity to discover beneficial, complementary treatment approaches and yield significant 
reductions in morbidity and mortality. The challenge that we now face, and that will continue to grow, is learning how to maximize the benefits from multiple effective agents_-rather than the previous challenge of having little to offer these patients.

\section{REFERENCES}

Accurso FJ, Rowe SM, Clancy JP, Boyle MP, Dunitz JM, Durie PR, Sagel SD, Hornick DB, Konstan MW, Donaldson SH, et al. 2010. Effect of VX-770 in persons with cystic fibrosis and the G551D-CFTR mutation. $N$ Engl J Med 363: 1991-2003.

Accurso FJ, Moss RB, Wilmott RW, Anbar RD, Schaberg AE, Durham TA, Ramsey BW, TIGER-1 Investigator Study Group. 2011. Denufosol tetrasodium in patients with cystic fibrosis and normal to mildly impaired lung function. Am J Respir Crit Care Med 183: 627-634.

Anderson MP, Welsh MJ. 1991. Calcium and cAMP activate different chloride channels in the apical membrane of normal and cystic fibrosis epithelia. Proc Natl Acad Sci 88: 6003-6007.

Bennett WD, Olivier KN, Zeman KL, Hohneker KW, Boucher RC, Knowles MR. 1996. Effect of uridine 5'triphosphate plus amiloride on mucociliary clearance in adult cystic fibrosis. Am J Respir Crit Care Med 153: 1796-1801.

Bilton D, Robinson P, Cooper P, Charlton B. 2009. Randomized, double blind, placebo-controlled phase iii study of inhaled dry powder mannitol (Bronchitol) in CF. Pediatr Pulmonol 44 (Suppl): A216.

Bridges RJ, Newton BB, Pilewski JM, Devor DC, Poll CT, Hall RL. 2001. $\mathrm{Na}^{+}$transport in normal and CF human bronchial epithelial cells is inhibited by BAY 39-9437. Am J Physiol Lung Cell Mol Physiol 281: L16-L23.

Caldwell RA, Boucher RC, Stutts MJ. 2005. Neutrophil elastase activates near-silent epithelial $\mathrm{Na}^{+}$channels and increases airway epithelial $\mathrm{Na}^{+}$transport. Am J Physiol Lung Cell Mol Physiol 288: L813-L819.

Caputo A, Caci E, Ferrera L, Pedemonte N, Barsanti C, Sondo E, Pfeffer U, Ravazzolo R, Zegarra-Moran O, Galietta LJ. 2008. TMEM16A, a membrane protein associated with calcium-dependent chloride channel activity. Science 322: 590-594.

Clarke LL, Harline MC, Otero MA, Glover GG, Garrad RC, Krugh B, Walker NM, González FA, Turner JT, Weisman GA. 1999. Desensitization of P2Y2 receptoractivated transepithelial anion secretion. Am J Physiol 276: C777-C787.

Coakley RD, Grubb BR, Paradiso AM, Gatzy JT, Johnson LG, Kreda SM, O'Neal WK, Boucher RC. 2003. Abnormal surface liquid $\mathrm{pH}$ regulation by cultured cystic fibrosis bronchial epithelium. Proc Natl Acad Sci 100: 1608316088.

Conner GE, Wijkstrom-Frei C, Randell SH, Fernandez VE, Salathe M. 2007. The lactoperoxidase system links anion transport to host defense in cystic fibrosis. FEBS Lett 581: $271-278$.
Coote K, Atherton-Watson HC, Sugar R, Young A, MacKenzie-Beevor A, Gosling M, Bhalay G, Bloomfield G, Dunstan A, Bridges RJ, et al. 2009. Camostat attenuates airway epithelial sodium channel function in vivo through the inhibition of a channel-activating protease. J Pharmacol Exp Ther 329: 764-774.

Daviskas E, Anderson SD, Brannan JD, Chan HK, Eberl S, Bautovich G. 1997. Inhalation of dry-powder mannitol increases mucociliary clearance. Eur Respir J 10: 24492454.

Daviskas E, Anderson SD, Eberl S, Chan HK, Bautovich G. 1999. Inhalation of dry powder mannitol improves clearance of mucus in patients with bronchiectasis. Am J Respir Crit Care Med 159: 1843-1848.

Daviskas E, Anderson SD, Eberl S, Chan HK, Young IH. 2001. The 24-h effect of mannitol on the clearance of mucus in patients with bronchiectasis. Chest 119: 414421.

Daviskas E, Anderson SD, Eberl S, Young IH. 2008. Effect of increasing doses of mannitol on mucus clearance in patients with bronchiectasis. Eur Respir J 31: 765-772.

Daviskas E, Anderson SD, Jaques A, Charlton B. 2010. Inhaled mannitol improves the hydration and surface properties of sputum in patients with cystic fibrosis. Chest 137: 861-868.

Deterding R, Retsch-Bogart G, Milgram L, Gibson R, Daines C, Zeitlin PL, Milla C, Marshall B, Lavange L, Engels J, et al. 2005. Safety and tolerability of denufosol tetrasodium inhalation solution, a novel P2Y2 receptor agonist: Results of a phase 1 / phase 2 multicenter study in mild to moderate cystic fibrosis. Pediatr Pulmonol 39: $339-348$.

Deterding RR, Lavange LM, Engels JM, Mathews DW, Coquillette SJ, Brody AS, Millard SP, Ramsey BW, Cystic Fibrosis Therapeutics Development Network Inspire 08103 Working Group. 2007. Phase 2 randomized safety and efficacy trial of nebulized denufosol tetrasodium in cystic fibrosis. Am J Respir Crit Care Med 176: 362-369.

Donaldson SH, Hirsh A, Li DC, Holloway G, Chao J, Boucher RC, Gabriel SE. 2002. Regulation of the epithelial sodium channel by serine proteases in human airways. J Biol Chem 277: 8338-8345.

Donaldson S, Smith R, Doran J, DiMassimo B, Zeman K, Bennett B, Hurd H, Hopkins S. 2005. Safety, pharmacokinetics and effects on mucus clearance following administration of 552-02 to normal healthy volunteers. Pediatr Pulmonol 28 (Suppl): 218.

Donaldson SH, Bennett WD, Zeman KL, Knowles MR, Tarran R, Boucher RC. 2006. Mucus clearance and lung function in cystic fibrosis with hypertonic saline. New Engl J Med 354: 241-250.

Elkins MR, Robinson M, Rose BR, Harbour C, Moriarty CP Marks GB, Belousova EG, Xuan W, Bye PT, National Hypertonic Saline in Cystic Fibrosis (NHSCF) Study Group. 2006. A controlled trial of long-term inhaled hypertonic saline in patients with cystic fibrosis. N Engl J Med 354: 229-240.

Fragoso MA, Fernandez V, Forteza R, Randell SH, Salathe M, Conner GE. 2004. Transcellular thiocyanate transport by human airway epithelia. J Physiol 561: 183-194.

Galietta LJ. 2009. The TMEM16 protein family: A new class of chloride channels? Biophys J 97: 3047-3053. 
S.H. Donaldson and L. Galietta

Galietta LJ, Pagesy P, Folli C, Caci E, Romio L, Costes B, Nicolis E, Cabrini G, Goossens M, Ravazzolo R, et al. 2002. IL-4 is a potent modulator of ion transport in the human bronchial epithelium in vitro. J Immunol 168: 839-845.

Garcia MA, Yang N, Quinton PM. 2009. Normal mouse intestinal mucus release requires cystic fibrosis transmembrane regulator-dependent bicarbonate secretion. J Clin Invest 119: 2613-2622.

Garcia-Caballero A, Dang Y, He H, Stutts MJ. 2008. ENaC proteolytic regulation by channel-activating protease 2 . J Gen Physiol 132: 521-535.

Garcia-Caballero A, Rasmussen JE, Gaillard E, Watson MJ, Olsen JC, Donaldson SH, Stutts MJ, Tarran R. 2009. SPLUNC1 regulates airway surface liquid volume by protecting ENaC from proteolytic cleavage. Proc Natl Acad Sci 106: $11412-11417$.

Gentzsch M, Dang H, Dang Y, Garcia-Caballero A, Suchindran H, Boucher RC, Stutts MJ. 2010. The cystic fibrosis transmembrane conductance regulator impedes proteolytic stimulation of the epithelial $\mathrm{Na}^{+}$channel. J Biol Chem 285: 32227-32232.

Gerson C, Sabater J, Scuri M, Torbati A, Coffey R, Abraham JW, Lauredo I, Forteza R, Wanner A, Salathe M, et al. 2000. The lactoperoxidase system functions in bacterial clearance of airways. Am J Respir Cell Mol Biol 22: 665671.

Graham A, Hasani A, Alton EW, Martin GP, Marriott C, Hodson ME, Clarke SW, Geddes DM. 1993. No added benefit from nebulized amiloride in patients with cystic fibrosis. Eur Respir J 6: 1243-1248.

Grasemann H, Stehling F, Brunar H, Widmann R, Laliberte TW, Molina L, Döring G, Ratjen F. 2007. Inhalation of Moli1901 in patients with cystic fibrosis. Chest 131: 1461-1466.

Greenwood IA, Ledoux J, Leblanc N. 2001. Differential regulation of $\mathrm{Ca}^{2+}$-activated $\mathrm{Cl}^{-}$currents in rabbit arterial and portal vein smooth muscle cells by $\mathrm{Ca}^{2+}$-calmodulin-dependent kinase. J Physiol 534: 395-408.

Hirsh AJ, Zhang J, Zamurs A, Fleegle J, Thelin WR, Caldwell RA, Sabater JR, Abraham WM, Donowitz M, Cha B, et al. 2008. Pharmacological properties of $N$-(3,5-diamino-6-chloropyrazine-2-carbonyl)- $N^{\prime}$-4-[4-(2,3-dihydroxypropoxy) phenyl]butyl-guanidine methanesulfonate (552-02), a novel epithelial sodium channel blocker with potential clinical efficacy for cystic fibrosis lung disease. J Pharmacol Exp Ther 325: 77-88.

Illek B, Yankaskas JR, Machen TE. 1997. cAMP and genistein stimulate $\mathrm{HCO} 3$ - conductance through CFTR in human airway epithelia. Am J Physiol 272: L752-L761.

Jaques A, Daviskas E, Turton JA, McKay K, Cooper P, Stirling RG, Robertson CF, Bye PT, Lesouëf PN, Shadbolt B, et al. 2008. Inhaled mannitol improves lung function in cystic fibrosis. Chest 133: 1388-1396.

Kimura T, Kawabe H, Jiang C, Zhang W, Xiang YY, Lu C, Salter MW, Brose N, Lu WY, Rotin D. 2011. Deletion of the ubiquitin ligase Nedd4 L in lung epithelia causes cystic fibrosis-like disease. Proc Natl Acad Sci 108: $3216-$ 3221.

Knowles M, Gatzy J, Boucher R. 1981. Increased bioelectric potential difference across respiratory epithelia in cystic fibrosis. N Engl J Med 305: 1489-1495.
Knowles MR, Church NL, Waltner WE, Yankaskas JR, Gilligan P, King M, Edwards LJ, Helms RW, Boucher RC. 1990. A pilot study of aerosolized amiloride for the treatment of lung disease in cystic fibrosis. N Engl J Med 322: 1189-1194.

Knowles MR, Clarke LL, Boucher RC. 1991. Activation by extracellular nucleotides of chloride secretion in the airway epithelia of patients with cystic fibrosis [see comments]. N Engl J Med 325: 533-538.

Knowles MR, Church NL, Waltner WE, et al. 1992. Amiloride in CF: Safety, pharmacokinetics, and efficacy in the treatment of pulmonary disease. In Amiloride and its analogs: Unique cation transport inhibitors (ed. Cragoe EJ, et al.), pp. 301-316. VCH, Chichester, U.K.

Kohler D, App E, Schmitz-Schumann M, Wurtemberger G, Matthys H. 1986. Inhalation of amiloride improves the mucociliary and the cough clearance in patients with cystic fibroses. Eur Respir J Dis Suppl 146: 319-326.

Mall M, Grubb BR, Harkema JR, O’Neal WK, Boucher RC. 2004. Increased airway epithelial $\mathrm{Na}^{+}$absorption produces cystic fibrosis-like lung disease in mice. Nat Med 10: $487-493$.

Mason SJ, Paradiso AM, Boucher RC. 1991. Regulation of transepithelial ion transport and intracellular calcium by extracellular ATP in human normal and cystic fibrosis airway epithelium. Br J Pharmacol 103: 1649-1656.

Matsui H, Grubb BR, Tarran R, Randell SH, Gatzy JT, Davis CW, Boucher RC. 1998. Evidence for periciliary liquid layer depletion, not abnormal ion composition, in the pathogenesis of cystic fibrosis airways disease. Cell 95: 1005-1015.

Minasian C, Wallis C, Metcalfe C, Bush A. 2010. Comparison of inhaled mannitol, daily rhDNase and a combination of both in children with cystic fibrosis: A randomised trial. Thorax 65: 51-56.

Moskwa P, Lorentzen D, Excoffon KJ, Zabner J, McCray PB Jr, Nauseef WM, Dupuy C, Bánfi B. 2007. A novel host defense system of airways is defective in cystic fibrosis. Am J Respir Crit Care Med 175: 174-183.

Myerburg MM, Butterworth MB, McKenna EE, Peters KW, Frizzell RA, Kleyman TR, Pilewski JM. 2006. Airway surface liquid volume regulates $\mathrm{ENaC}$ by altering the serine protease-protease inhibitor balance: A mechanism for sodium hyperabsorption in cystic fibrosis. J Biol Chem 281: 27942-27949.

Myerburg MM, McKenna EE, Luke CJ, Frizzell RA, Kleyman TR, Pilewski JM. 2008. Prostasin expression is regulated by airway surface liquid volume and is increased in cystic fibrosis. Am J Physiol Lung Cell Mol Physiol 294: L932-L941.

Myerburg MM, Harvey PR, Heidrich EM, Pilewski JM, Butterworth MB. 2010. Acute regulation of the epithelial sodium channel in airway epithelia by proteases and trafficking. Am J Res Cell Mol Biol 43: 712-719.

Namkung W, Phuan PW, Verkman AS. 2011. TMEM16A inhibitors reveal TMEM16A as a minor component of calcium-activated chloride channel conductance in airway and intestinal epithelial cells. J Biol Chem 286: 2365-2374.

Noone PG, Bennett WD, Regnis JA, Zeman KL, Carson JL, King M, Boucher RC, Knowles MR. 1999. Effect of aerosolized uridine- $5^{\prime}$-triphosphate on airway clearance with 
cough in patients with primary ciliary dyskinesia. Am J Respir Crit Care Med 160: 144-149.

Olivier KN, Bennett WD, Hohneker KW, Zeman KL, Edwards LJ, Boucher RC, Knowles MR. 1996. Acute safety and effects on mucociliary clearance of aerosolized uridine $5^{\prime}$-triphosphate $+/-$ amiloride in normal human adults. Am J Respir Crit Care Med 154: 217-223.

Ousingsawat J, Martins JR, Schreiber R, Rock JR, Harfe BD, Kunzelmann K. 2009. Loss of TMEM16A causes a defect in epithelial $\mathrm{Ca}^{2+}$-dependent chloride transport. J Biol Chem 284: 28698-28703.

Picher M, Burch LH, Boucher RC. 2004. Metabolism of P2 receptor agonists in human airways: Implications for mucociliary clearance and cystic fibrosis. J Biol Chem 279: 20234-20241.

Robinson M, Daviskas E, Eberl S, Baker J, Chan HK, Anderson SD, Bye PT. 1999. The effect of inhaled mannitol on bronchial mucus clearance in cystic fibrosis patients: A pilot study. Eur Respir J 14: 678-685.

Rock JR, O’Neal WK, Gabriel SE, Randell SH, Harfe BD, Boucher RC, Grubb BR. 2009. Transmembrane protein 16A (TMEM16A) is a $\mathrm{Ca}^{2+}$-regulated $\mathrm{Cl}^{-}$secretory channel in mouse airways. J Biol Chem 284: $14875-$ 14880 .

Rollins BM, Garcia-Caballero A, Stutts MJ, Tarran R. 2010 SPLUNC1 expression reduces surface levels of the epithelial sodium channel $(\mathrm{ENaC})$ in Xenopus laevis oocytes. Channels (Austin) 4: 255-259.

Schroeder BC, Cheng T, Jan YN, Jan LY. 2008. Expression cloning of TMEM16A as a calcium-activated chloride channel subunit. Cell 134: 1019-1029.

Smith JJ, Welsh MJ. 1992. cAMP stimulates bicarbonate secretion across normal, but not cystic fibrosis airway epithelia. J Clin Invest 89: 1148-1153.

Stutts MJ, Canessa CM, Olsen JC, Hamrick M, Cohn JA, Rossier BC, Boucher RC. 1995. CFTR as a cAMP-dependent regulator of sodium channels [see comments]. Science 269: 847-850.

Tarran R, Loewen ME, Paradiso AM, Olsen JC, Gray MA, Argent BE, Boucher RC, Gabriel SE. 2002. Regulation of murine airway surface liquid volume by CFTR and $\mathrm{Ca}^{2+}$. activated $\mathrm{Cl}^{-}$conductances. J Gen Physiol 120: 407-418.

Tarran R, Button B, Picher M, Paradiso AM, Ribeiro CM, Lazarowski ER, Zhang L, Collins PL, Pickles RJ, Fredberg JJ, et al. 2005. Normal and cystic fibrosis airway surface liquid homeostasis: The effects of phasic shear stress and viral infections. J Biol Chem 280: 3575135759 .
Tarran R, Trout L, Donaldson SH, Boucher RC. 2006. Soluble mediators, not cilia, determine airway surface liquid volume in normal and cystic fibrosis superficial airway epithelia. J Gen Physiol 127: 591-604.

Tarran R, Donaldson S, Boucher RC. 2007. Rationale for hypertonic saline therapy for cystic fibrosis lung disease. Semin Respir Crit Care Med 28: 295-302.

Teper A, Jaques A, Charlton B. 2011. Inhaled mannitol in patients with cystic fibrosis: A randomised open-label dose response trial. J Cystic Fibrosis 10: 1-8.

Tian Y, Kongsuphol P, Hug M, Ousingsawat J, Witzgall R, Schreiber R, Kunzelmann K. 2011. Calmodulin-dependent activation of the epithelial calcium-dependent chloride channel TMEM16A. FASEB J 25: 1058-1068.

Verkman AS, Galietta LJ. 2009. Chloride channels as drug targets. Nat Rev Drug Discov 8: 153-171.

Vuagniaux G, Vallet V, Jaeger NF, Hummler E, Rossier BC. 2002. Synergistic activation of $\mathrm{ENaC}$ by three membranebound channel-activating serine proteases (mCAP1, mCAP2, and mCAP3) and serum- and glucocorticoidregulated kinase (Sgk1) in Xenopus Oocytes. J Gen Physiol 120: 191-201.

Wagner JA, Cozens AL, Schulman H, Gruenert DC, Stryer L, Gardner P. 1991. Activation of chloride channels in normal and cystic fibrosis airway epithelial cells by multifunctional calcium/calmodulin-dependent protein kinase. Nature 349: 793-796.

Wang YX, Kotlikoff MI. 1997. Inactivation of calcium-activated chloride channels in smooth muscle by calcium/ calmodulin-dependent protein kinase. Proc Natl Acad Sci 94: 14918-14923.

Willumsen NJ, Boucher RC. 1991. Transcellular sodium transport in cultured cystic fibrosis human nasal epithelium. Am J Physiol 261: C332-C341.

Xie W, Kaetzel MA, Bruzik KS, Dedman JR, Shears SB, Nelson DJ. 1996. Inositol 3,4,5,6-tetrakisphosphate inhibits the calmodulin-dependent protein kinase II-activated chloride conductance in T84 colonic epithelial cells. J Biol Chem 271: 14092-14097.

Yang YD, Cho H, Koo JY, Tak MH, Cho Y, Shim WS, Park SP, Lee J, Lee B, Kim BM, et al. 2008. TMEM16A confers receptor-activated calcium-dependent chloride conductance. Nature 455: 1210-1215.

Zeitlin PL, Boyle MP, Guggino WB, Molina L. 2004. A phase I trial of intranasal Moli1901 for cystic fibrosis. Chest 125: 143-149. 


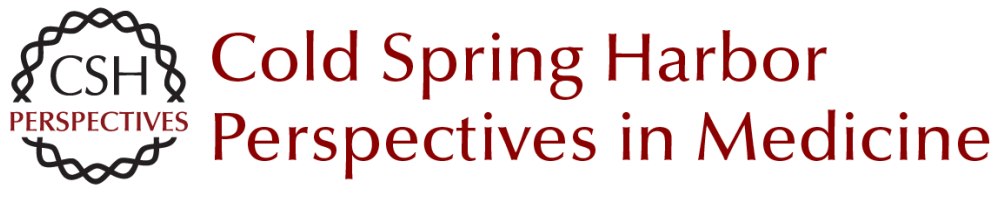

\section{New Pulmonary Therapies Directed at Targets Other than CFTR}

Scott H. Donaldson and Luis Galietta

Cold Spring Harb Perspect Med 2013; doi: 10.1101/cshperspect.a009787

Subject Collection Cystic Fibrosis

Antibiotic and Anti-Inflammatory Therapies for

Cystic Fibrosis

James F. Chmiel, Michael W. Konstan and J. Stuart Elborn

Structure and Function of the Mucus Clearance System of the Lung

Brenda M. Button and Brian Button

New Pulmonary Therapies Directed at Targets

Other than CFTR

Scott H. Donaldson and Luis Galietta

The Cystic Fibrosis Airway Microbiome

Susan V. Lynch and Kenneth D. Bruce

\section{Cystic Fibrosis Transmembrane Conductance \\ Regulator (ABCC7) Structure \\ John F. Hunt, Chi Wang and Robert C. Ford}

Status of Fluid and Electrolyte Absorption in

Cystic Fibrosis

M.M. Reddy and M. Jackson Stutts

The Influence of Genetics on Cystic Fibrosis

Phenotypes

Michael R. Knowles and Mitchell Drumm

Perspectives on Mucus Properties and Formation

--Lessons from the Biochemical World

Daniel Ambort, Malin E.V. Johansson, Jenny K.

Gustafsson, et al.
The Cystic Fibrosis Intestine

Robert C. De Lisle and Drucy Borowitz

Cystic Fibrosis Transmembrane Regulator

Correctors and Potentiators

Steven M. Rowe and Alan S. Verkman

The Cystic Fibrosis of Exocrine Pancreas

Michael Wilschanski and Ivana Novak

Dynamics Intrinsic to Cystic Fibrosis

Transmembrane Conductance Regulator Function and Stability

P. Andrew Chong, Pradeep Kota, Nikolay V.

Dokholyan, et al.

The Cystic Fibrosis Gene: A Molecular Genetic

Perspective

Lap-Chee Tsui and Ruslan Dorfman

The CFTR Ion Channel: Gating, Regulation, and

Anion Permeation

Tzyh-Chang Hwang and Kevin L. Kirk

Assessing the Disease-Liability of Mutations in CFTR

Claude Ferec and Garry R. Cutting

Supramolecular Dynamics of Mucus Pedro Verdugo

For additional articles in this collection, see http://perspectivesinmedicine.cshlp.org/cgi/collection/ 